\title{
The Power of 'Wow' to Attract New Customers
}

\section{Eden Blair (Bradley University)}

KEYWORDS: Entrepreneurship, Marketing, Product Development.

Years ago, millions of consumers discovered something that they never knew they needed: TIVO, which ultimately would change the way they watched television and disrupt an entire industry. That discovery shows how a truly unique product can become a must-have for consumers who never envisioned it before. But do inventors conjure up these products, or are they inspired by asking the market what it needs? Eden Blair, a professor at Bradley University in Illinois, says it's a little of both. 